\title{
Work Stress and its Relationship to the Teaching Competencies from the Physical Education Teachers' Standpoint in the State of Kuwait
}

\author{
Dr. Hamad Sttar Jaber Al-Anazi \\ The Ministry of Education, State of Kuwait
}

\begin{abstract}
This study aims to identify the degree of work stress and its relationship to the teaching competencies from the physical education teachers' standpoint in the State of Kuwait. The study uses a descriptive approach based on the correlational method. The study population consists of all male and female teachers of physical education in public secondary schools in the State of Kuwait. As for the study sample, it consists of (241) male and female teachers of physical education selected by the stratified random method. Data collection is prepared, and the instrument validity is verified through the validators' validity and the internal consistency, and the instrument reliability is also verified using the Cronbach's alpha formula.

The results show that the degree of work stress for physical education teachers in the State of Kuwait in all dimensions is in the medium degree except for the dimension of "Stresses related to the educational supervisor" which is in the high degree. The results also show that the degree of physical education teachers' practice of the teaching competencies in the State of Kuwait in all dimensions is in the high degree, except for the "Assessment competencies of educational outcomes" which is in the medium degree. The results also show that there are negative, weak or very weak correlations between the degree of work stress and its various dimensions on the one hand, and the degree of practicing teaching competencies and their dimensions on the other hand.

The study recommends conducting constantly training courses for physical education teachers with short experience to familiarize them with how to face, address and overcome work stresses, along with the necessity of paying attention of the pedagogical inspectors of physical education to work to raise the practice of physical education teachers to the assessment competencies of educational outcomes.
\end{abstract}

DOI: $10.7176 / \mathrm{JEP} / 11-4-08$

Publication date: February $29^{\text {th }} 2020$

\subsection{Introduction}

Physical education teachers face many problems varying according to the factors that cause them in this life. Physical education teachers face uneasy circumstances and situations that may expose them to stresses in the work environment, which have effects and negatives that are reflected in their psychological and physical condition, showing symptoms of tension, frustration, and anxiety, which negatively affect their performance and teaching competencies.

Work stress is one of the most important features of the contemporary era, which is witnessing rapid developments and changes in all areas of life. Work stress has become part of human life due to the many challenges it faces, and therefore it is almost spread in various environments, especially in the business environment that requires from those in charge of it to have a direct interaction with people like employees in the teaching profession (Masdar and Abu Kweik, 2007).

The work stress for the teacher is one of the most important obstacles to the progress of the educational process as required. It is also one of the main factors in the imbalance of the educational system, and the teacher's suffering from the sources of stress formatted is a state of tension and strain resulting from working conditions, and within this framework, the stress indicates the presence of external causes or sources, as there are internal reactions due to these stressful sources (Malika, 2011).

During the exercise of his work, the teacher may feel physical, psychological or mental fatigue, and this may be due to the physical or mental charge borne by the teacher during his work, which costs him to exert great effort and energy. This physical effort may result in a state of fatigue that makes the teacher in an uncomfortable position other, as the mental burden also causes mental fatigue which makes it impossible to continue the activity. The position of not continuing the activity creates a state of imbalance that may lead to stress, and thus it is concluded that fatigue and exhaustion at work lead stress on the teacher (Muslim, 2007).

Khleifat and Matarneh (2010) define work stress as a set of interactions between an individual and his environment, which causes an unpleasant emotional state such as stress and anxiety. It is also seen as the reactions that result from the interaction between the environmental conditions where the individual works, and the characteristics of the individual himself from the capabilities, skills, and experiences, which affect the response of individuals to the various internal and external environmental stimuli, and thus the individual dissimilarities differ in the degree of responsibility towards those stimuli. 
Ismail and Aziz (2010) define the work stress of the physical education teacher as a set of negative factors that exist in the work of the physical education teacher environment, which caused an imbalance in his physical and psychological case, affecting the ability to improve his job requirements.

Given that the teaching profession is considered one of the stressful social professions that have many sources of stress that make some teachers unsure and dissatisfied with their profession, which affects their psychological compatibility and job satisfaction with their various work (Hamaideh, 2011). Given that the importance of the role that the competent teacher plays in the educational process mentioned in some studies such as the 2004 study of Pines that showed that work stresses are often experienced by enthusiastic, competent and loyal teachers at work due to the difficult circumstances facing them, and therefore the lack of disclosure of work stresses facing teachers in general and physical education teachers in particular leads to an increase in those stresses and their negative impact on their professional performance. Muslim (2007) believes that employees 'exposure to work stresses may threaten the practices of their profession due to the negative effects that arise from these stresses, such as dissatisfaction with their profession, their inability to innovate, and weak motivation to work, their feeling of psychological and physical exhaustion, and their poor level of teaching competence, and this, in turn, is reflected in the students 'achievement.

Consequently, this study aims to reveal the degree of work stress and its relationship to the teaching competencies of physical education teachers in the State of Kuwait. This study is encouraged by the lack of studies conducted in Kuwait based on the researchers' knowledge on concerning this topic despite the interest of writers and researchers in the field of education to identify the sources of work stress the teacher is exposed to reduce its impact on teachers which is reflected on their teaching competencies for students.

\subsection{Problem of the Study}

The problem of the study stems from the teachers 'daily exposure to different levels of work stress as a result of the developments that have entered in different areas of life from the communication revolution and the entry of technology in the different fields of education. These new developments have left psychological, social and economic effects reflected on the teachers' level of performance, and their assigned educational duties and tasks, which often leads to instances of disorder, anxiety, frustration, and physical and psychological fatigue.

The important role played by a male and female physical education teacher in preparing students, and the accompanying physical and intellectual effort may contribute to the creation of work stress for the teacher. Teachers are among the most vulnerable people to stress, as the results of the 2009 study of Kuchinsky indicated that the teaching profession is one of the professions that greatly put stress on its workers, where the physical education teacher, like other education employees, is subject to a lot of work stress represented by the increase in number of students in one class, the increasing number of weekly classes, and the consequent job burdens that may be reflected in their teaching competencies.

Such conditions create a sense of loss of interest in the work of a physical education teacher, and may eventually lead him/her to leave the profession and search for another profession (Zahir and Mashhadani, 2012). So, it is of great importance to identify the work stress that physical education teachers are exposed to in the Kuwaiti schools and their relationship to teaching competencies to face those stresses and develop appropriate solutions for them so that the physical education teacher in the State of Kuwait can practice the teaching competencies necessary to do his/her duty in full. Against this, the problem of the study is summarized in revealing the degree of work stress among physical education teachers in the State of Kuwait, identifying the degree of their practice of teaching competencies, as well as exploring the relationship between work stresses and teaching competence of physical education teachers in the State of Kuwait.

\subsection{Questions of the Study}

In light of the problem of the study, the following questions are formatted.

1- What is the degree of work stress from physical education teachers' standpoint in the State of Kuwait?

2- What is the degree of practicing teaching competencies from physical education teachers' standpoint in the State of Kuwait?

\subsection{Objectives of the Study}

In light of the questions of the study, the following objectives are formatted.

1. Reveal the degree of work stress and its relationship to the teaching competencies from the physical education teachers' standpoint in the State of Kuwait.

\subsection{Significance of the Study}

The importance of this study lies in the fact that it highlights the extent of the suffering of physical education teachers in the schools of the State of Kuwait as a result of their exposure to work stress in the education profession, and the effects and problems that may negatively affect their psychological and physical health. 
Therefore, the results of this study may help them avoid work stress as much as possible, deal with it and manage it effectively, and this will improve their effectiveness in practicing teaching competencies. The practical importance of the study is demonstrated through its findings and recommendations, which may help in identifying the causes of work stresses for physical education teachers, determining their levels, and setting appropriate goals and means to reduce them. This will contribute to advance the teaching of the physical education course in the State of Kuwait and improve teaching competencies among teachers

\subsection{Previous Studies}

Several studies have paid attention to the degree of work stress among physical education teachers. In his 2005 study, Saleh aims at identifying work stresses and differences in occupational stresses among physical education teachers in Iraq. The study sample consisted of (52) male and female teachers of physical education in the intermediate and preparatory stages in Diyala Governorate/ Al-Khalis district. The researcher used a measure of work stress for a physical education teacher, which consists of (36) items distributed on six factors of professional stress, which are: factors related to working with students, factors related to the school's financial capabilities, factors related to the teacher's monthly salary, factors related to physical educational supervision, factors related to the relationship between the teacher and the school management, and factors related to relations with teachers. The results have shown that the level of work stress among physical education teachers was at a high level. The results also showed that there were statistically significant differences in the occupational stresses between each of the teachers of the intermediate and preparatory stages in favor of middle school teachers, and the absence of statistically significant differences in the stress of the profession due to the gender variable. In his 2020 study, Sharif aims at assessing the teaching competencies of female teachers in the field of physical education at Alexandria University in the light of academic quality standards. The sample of the study consisted of (59) female teachers in cooperating schools in the city of Alexandria. The results of the study showed that the teachers possess three highly qualified teaching competencies, which are respectively: cognitive competencies (such as formulating general and special goals), and performance competencies (such as creating an effective and safe classroom environment), emotional competencies (such as respecting the student's personality). The results also indicated that female teachers possess low educational production competencies.

In their 2011 study, Bhargava \& Pathy investigate the teaching competencies that teachers need to succeed in the teaching profession from their point of view. The study sample consisted of (100) a pre-service teacher in the specialty of education at the University of Ranchi, India, and a questionnaire was used for data collection. The results of the study indicated that the most needed personal competency by teachers is the adequacy of selfconfidence and that the most professional competency needed by them is the adequacy of knowledge of the content of the subject that they teach to school students.

In his 2015 study, Hamad identifies the stresses of work and its relationship to the job performance of male and female independent school teachers in Qatar. It also aims to show the effect of gender, nationality, educational qualification and stage of study in the main variables of the study. The study sample consisted of (395) teachers, who were randomly selected. To achieve the goals of the study, two questionnaires were developed as follows: the first to explore work stress, and the second to reveal the level of the job performance of male and female teachers. Among the most important findings of the study is that the level of work stress among teachers in independent schools in the State of Qatar was medium in the areas of students, parents, family stress, teaching and working conditions, management and supervision, and curricula. It is also seen that the level of the job performance of male and female teachers was high in the fields of teaching, human relations, monitoring and evaluation, planning and professional development. The results also showed that there are statistically significant differences at the level of work stress caused by the gender variable in favor of males in the field of curricula only, and there was a statistically significant correlation between work stress and job performance of teachers in the field of managing stress, supervision, teaching, working conditions and curricula.

\subsection{Operational Definitions}

The study included several terms that are conceptually and procedurally defined as follows:

Work stress: the unusual working conditions that a teacher is exposed to while practicing the teaching profession, which may exceed his capabilities and constitute stress that he cannot bear, leading to problems that affect his physical, psychological, and social health (Talafha, 2013).

Teaching competencies: capabilities that are expressed in behavioral terms that include a set of tasks (cognitive, skilled and emotional) that constitute the final performance expected from the teacher at a certain satisfactory level in terms of effectiveness, which can be observed and evaluated by different means of observation (Fatlawi, 2003).

\subsection{Methodology of the Study}

Since the study reveals the degree of work stress and the degree of practicing teaching competencies among 
physical education teachers in the State of Kuwait and finds the correlation between work stress and the degree of teachers exercising teaching competencies, the approach adopted by the study is the descriptive approach according to the correlational method for its suitability to achieve the goals of the study.

\subsection{Population Study}

The study population consists of all physical education teachers in public secondary schools at the Ministry of Education in the State of Kuwait

\subsection{Study Sample}

The study sample was selected according to the random sample method, which gives each member in the study population equal opportunities. The number of the sample population reached (241) members from male and female teachers of physical education in public schools as shown in Table (1).

Table 1: Frequencies and Percentages According to the Study Variables

\begin{tabular}{|l|l|l|l|}
\hline Variable & Variable Categories & Number & Percentage \\
\hline \multirow{3}{*}{ Teacher Gender } & Male & 119 & $49.38 \%$ \\
\cline { 2 - 4 } & Female & 122 & $50.62 \%$ \\
\cline { 2 - 4 } & Total & 241 & $100 \%$ \\
\hline \multirow{2}{*}{$\begin{array}{l}\text { Teaching Experience of } \\
\text { the Teacher }\end{array}$} & Less than 5 years & 52 & $21.58 \%$ \\
\cline { 2 - 4 } & From 5 to 10 years & 91 & $37.76 \%$ \\
\cline { 2 - 4 } & More than 10 years & 98 & $40.66 \%$ \\
\cline { 2 - 4 } & Total & 241 & $100 \%$ \\
\hline
\end{tabular}

\subsection{Study Instrument}

To achieve the aims of the study, theoretical literature and previous studies that address good citizenship such as the 2015 study of Hamad (2015) and other related studies have been explored.

\subsection{Study Validity}

To verify the validity of the instrument, it was presented to a group of validators to judge the degree of suitability of the items in terms of their formulation, their suitability for the field, and the degree of their achievement of the intended goal, and the opinions of the validators are taken into consideration in terms of deletion, modification, and addition, and then the finalization of the questionnaire.

\subsection{Study Reliability}

After verifying the validity of the study instrument's internal consistency, the reliability coefficients for the study instrument dimensions were calculated using the Cronbach's alpha formula, and the results were as shown in Table (2).

Table 2: Reliability Coefficients for the Study Instrument dimensions using the Alpha Cronbach Formula

\begin{tabular}{|l|l|l|l|}
\hline Questionnaire Parts & Dimensions & $\begin{array}{l}\text { No. } \\
\text { Items }\end{array}$ & $\begin{array}{l}\text { Coefficient } \\
\text { Cronbach's } \\
\text { Formula }\end{array}$ \\
Alpha \\
\hline \multirow{3}{*}{$\begin{array}{l}\text { Work Stress for Physical } \\
\text { Education Teachers }\end{array}$} & School management stresses & 6 & 0.846 \\
\cline { 2 - 4 } & Educational supervisor stresses & 6 & 0.847 \\
\cline { 2 - 4 } & Stress related to dealing with students & 6 & 0.826 \\
\cline { 2 - 4 } & Stress related to fellow teachers & 6 & 0.845 \\
\cline { 2 - 4 } & Salary and financial rewards' stresses & 5 & 0.813 \\
\cline { 2 - 4 } $\begin{array}{l}\text { Teaching Competencies for } \\
\text { Physical Education teachers }\end{array}$ & Work stress (total) & 29 & 0.916 \\
\cline { 2 - 4 } & $\begin{array}{l}\text { Competencies for implementing the } \\
\text { lesson "Employing educational methods } \\
\text { and aids" }\end{array}$ & 7 & 0.854 \\
\cline { 2 - 4 } & $\begin{array}{l}\text { Competencies for assessment educational } \\
\text { outcomes }\end{array}$ & 7 & 0.879 \\
\cline { 2 - 4 } & Class management competencies & 7 & 0.894 \\
\cline { 2 - 4 } & Teaching competencies (total) & 29 & 0.948 \\
\hline
\end{tabular}

The criterion for judging the arithmetic means of the study instrument is determined by dividing it into three levels: low, medium, and high, according to the following formula:

Category Length $=$ Highest value of the substitute - The minimum value of the substitute $/$ Number of levels $=(5-1) / 3=1.33$ 
Accordingly, the following criterion is used to judge the responses of the study sample:

The low degree is less than 2.33 .

The medium degree is from 2.34 to 3.67 .

The high degree is from 3.68 to 5.00

\section{Results and Discussion}

Results related to answering the first question: What is the degree of work stress from the physical education teachers' standpoint in the State of Kuwait?

To answer this question, arithmetic means and standard deviations were calculated as shown in Table (3):

Table (3) Arithmetic means and standard deviations for physical education teachers' estimations in the State of Kuwait

Table 3: Arithmetic Means and Standard Deviations for the Estimations of Physical Education Teachers in the State of Kuwait to the Degree of their Work Stress in General in Descending Order

\begin{tabular}{|l|l|l|l|l|}
\hline Rank & Dimension Text & AM & SD & Stress Degree \\
\hline 1 & Stresses related to educational supervisor & 3.79 & 0.51 & High \\
\hline 2 & Stresses related to School administration & 3.56 & 0.61 & Medium \\
\hline 3 & Stresses related to fellow teachers & 3.24 & 0.75 & Medium \\
\hline 4 & Stresses related to dealing with students & 3.01 & 0.69 & Medium \\
\hline Work stress (total) & 3.40 & 0.49 & Medium \\
\hline
\end{tabular}

Table (3) indicates that the degree of work stress for physical education teachers in the State of Kuwait, in general, is in the medium degree with an arithmetic mean of (3.40) and a standard deviation of (0.49)

As for the dimensions, the dimension of "stresses related to educational supervisor" ranked first with an arithmetic mean of (3.79) and a standard deviation of (0.51) with a high degree of appreciation, followed by the second dimension "stresses related to school administration" with an arithmetic average of (3.56) and a standard deviation of (0.61) and with a medium degree of appreciation. The dimension of "stresses related to fellow teachers" ranked third with an arithmetic mean of (3.24) and a standard deviation of (0.57) with an medium degree of appreciation, while the dimension of "stresses related to dealing with students" ranked fourth and last with an arithmetic mean of (3.01) and a standard deviation of (0.69) with a medium degree of appreciation.

As for the results of the items for each dimension of work stresses for physical education teachers, the results were as follows:

Results of the items related to the first dimension: stresses related to school administration

Table (4) shows the arithmetic means and the standard deviations of the estimations of physical education teachers in the State of Kuwait on the first dimension items, which measures work stresses related to school administration in descending order.

Table 4: Arithmetic Means and Standard Deviations for Physical Education Teachers' Estimations on the Items of the Dimension of "Stresses Related to School Administration" in Descending Order

\begin{tabular}{|l|l|l|l|l|l|}
\hline Rank & $\begin{array}{l}\text { No of } \\
\text { Item }\end{array}$ & Dimension of Stresses Related to School Administration & AM & SD & $\begin{array}{l}\text { Stresses } \\
\text { Degree }\end{array}$ \\
\hline 1 & 6 & $\begin{array}{l}\text { It disturbs me that most of the physical education classes were } \\
\text { placed by the school administration at the end of the school day }\end{array}$ & 3.86 & 0.86 & High \\
\hline 2 & 1 & $\begin{array}{l}\text { I suffer from the administration assigning to me additional } \\
\text { burdens that are not the core of my work }\end{array}$ & 3.75 & 0.73 & High \\
\hline 3 & 4 & $\begin{array}{l}\text { I feel the weakness of school administration's justice in } \\
\text { distributing the teaching quorum to teachers }\end{array}$ & 3.64 & 1.02 & Medium \\
\hline 4 & 2 & $\begin{array}{l}\text { I feel that school administration is affected by personal matters } \\
\text { when preparing annual teacher reports }\end{array}$ & 3.61 & 0.95 & Medium \\
\hline 5 & 3 & $\begin{array}{l}\text { I suffer from poor communication between me and the school } \\
\text { administration }\end{array}$ & 3.51 & 0.97 & Medium \\
\hline 6 & 5 & $\begin{array}{l}\text { I suffer from a lack of interest in school administration to provide } \\
\text { sports equipment in school }\end{array}$ & 2.97 & 1.08 & Medium \\
\hline
\end{tabular}

As for the dimensions, the dimension of "stresses related to educational supervisor" ranked first with an arithmetic mean of (3.79) and a standard deviation of (0.51) with a high degree of appreciation, followed by the second dimension "stresses related to school administration" with an arithmetic average of (3.56) and a standard deviation of (0.61) and with a medium degree of appreciation. The dimension of "stresses related to fellow teachers" ranked third with an arithmetic mean of (3.24) and a standard deviation of (0.57) with an medium degree of appreciation, while the dimension of "stresses related to dealing with students" ranked fourth and last with an arithmetic mean of (3.01) and a standard deviation of (0.69) with a medium degree of appreciation. 
Results of the items related to the second dimension: stresses related to the educational supervisor

Table (5) shows the arithmetic means and the standard deviations of the estimations of physical education teachers in the State of Kuwait on the first dimension items, which measures the work stress related to the educational supervisor in descending order.

Table 5: Arithmetic Means and Standard Deviations for Physical Education Teachers' Estimations on the Items of the Dimension of "Stresses Related to Educational Supervisor" in Descending Order

\begin{tabular}{|l|l|l|l|l|l|}
\hline Rank & $\begin{array}{l}\text { No of } \\
\text { Item }\end{array}$ & Dimension of Stresses Related to Educational Supervisor & AM & SD & $\begin{array}{l}\text { Stresses } \\
\text { Degree }\end{array}$ \\
\hline 1 & 10 & $\begin{array}{l}\text { I am concerned about the sudden visits of the educational } \\
\text { supervisor }\end{array}$ & 4.00 & 0.85 & High \\
\hline 2 & 12 & $\begin{array}{l}\text { It disturbs me the lack of interest in the physical education } \\
\text { supervisor to discuss the problems facing me }\end{array}$ & 3.90 & 0.92 & High \\
\hline 3 & 8 & $\begin{array}{l}\text { I suffer from a cold relationship between me and the physical } \\
\text { education supervisor }\end{array}$ & 3.80 & 0.89 & High \\
\hline 4 & 9 & $\begin{array}{l}\text { I see that mentor's instruction represents the power to intimidate } \\
\text { more than mentoring }\end{array}$ & 3.71 & 0.91 & High \\
\hline 5 & 7 & I feel the reports of the Physical Education supervisor are unfair & 3.67 & 0.88 & Medium \\
\hline 6 & 11 & $\begin{array}{l}\text { I think that the criteria the educational supervisor uses to } \\
\text { evaluate physical education teachers are inappropriate }\end{array}$ & 3.65 & 0.99 & Medium \\
\hline General arithmetic mean of the dimension & 3.79 & 0.51 & High \\
\hline
\end{tabular}

The results in Table (5) show that the arithmetic means ranged between (4.00-3.65), and the standard deviations for the items ranged between (0.85) and (0.99). Item (10) of " I am concerned about the sudden visits of the educational supervisor" ranked first with an arithmetic mean of (4.00) and a standard deviation of $(0.85)$ with a high degree of appreciation. While item (11) of " I think that the criteria the educational supervisor uses to evaluate physical education teachers are inappropriate " ranked last with an arithmetic mean of (3.65) and a standard deviation of (0.99), and with a medium degree of appreciation. This result can be explained by the fact that the visits of the educational counselor suddenly increase the confusion of the physical education teacher and make him feel constantly monitored, and that the physical education teachers are not aware of the criteria used to evaluate their performance.

Results of the paragraphs related to the third dimension: stresses related to dealing with students

Table (6) shows the arithmetic means and the standard deviations of the estimations of physical education teachers in the State of Kuwait on the third dimension items, which measures work stress related to dealing with students in descending order.

Table 6: Arithmetic Means and Standard Deviations for Physical Education Teachers' Estimations on the Items of the Dimension of "Stresses Related to Dealing with Students" in Descending Order.

\begin{tabular}{|l|l|l|l|l|l|}
\hline Rank & $\begin{array}{l}\text { No of } \\
\text { Item }\end{array}$ & Dimension of Stresses Related to Dealing with Students & AM & SD & $\begin{array}{l}\text { Stresses } \\
\text { Degree }\end{array}$ \\
\hline 1 & 16 & $\begin{array}{l}\text { I suffer from a lot of problems among students during the } \\
\text { lesson }\end{array}$ & 3.52 & 1.00 & Medium \\
\hline 2 & 15 & $\begin{array}{l}\text { Increasing student numbers does not help to benefit from the } \\
\text { lesson }\end{array}$ & 3.33 & 1.13 & Medium \\
\hline 3 & 13 & $\begin{array}{l}\text { I am annoyed by the low students 'respect for the physical } \\
\text { education teacher }\end{array}$ & 3.19 & 1.06 & Medium \\
\hline 4 & 14 & $\begin{array}{l}\text { I feel a decrease in the motivation of students towards } \\
\text { physical education lesson }\end{array}$ & 2.88 & 1.02 & Medium \\
\hline 5 & 17 & $\begin{array}{l}\text { The poor achievement of the students' required tasks bother } \\
\text { me }\end{array}$ & 2.73 & 0.97 & Medium \\
\hline 6 & 18 & $\begin{array}{l}\text { I feel bad that students are absent from physical education } \\
\text { lessons }\end{array}$ & 2.42 & 0.85 & Medium \\
\hline
\end{tabular}

The results in Table (6) indicate that the arithmetic means ranged between (3.52-2.42) and the standard deviations for the items ranged between (0.85) and (1.13). Item (16) of "I suffer from a lot of problems among students during the lesson" ranked first with an arithmetic mean of (3.52) and a standard deviation of (1.00) with a medium degree of appreciation. While item (18) of "I feel bad that students are absent from physical education lessons" ranked last with an arithmetic mean of (2.42) and a standard deviation of (0.85), with a medium degree of appreciation.

Perhaps, the reason for this result is that the physical education lessons are characterized by movement, 
activity, and interaction among students, which may lead to some problems among students during the lessons in the schoolyards, and that the students' attitudes towards sports activity are often positive, which leads them to make sure to participate in lessons physical education. This is also because the absence of students is one of the responsibilities of the school administration and the follow-up to the student guide in the school, which led to it coming in the last order from the physical education teacher.

Results of the items related to the fourth dimension: stress related to fellow teachers

Table (7) shows the arithmetic means and the standard deviations of the estimations of physical education teachers in the State of Kuwait on the fourth dimension items, which measure work stress related to in descending order.

Table (7): Arithmetic Means and Standard Deviations for Physical Education Teachers' Estimations on the Items of the Dimension of "Stresses Related to Fellow Teachers in Descending Order.

\begin{tabular}{|l|l|l|l|l|l|}
\hline Rank & $\begin{array}{l}\text { No of } \\
\text { Item }\end{array}$ & Dimension of Stresses Related to Fellow Teachers & AM & SD & $\begin{array}{l}\text { Stresses } \\
\text { Degree }\end{array}$ \\
\hline 1 & 21 & $\begin{array}{l}\text { My colleagues' criticism to the physical education lessons } \\
\text { disturbs me }\end{array}$ & 3.61 & 0.97 & Medium \\
\hline 2 & 19 & $\begin{array}{l}\text { I am annoyed by the lack of appreciation by some teachers of the } \\
\text { value of the work of the physical education teacher }\end{array}$ & 3.48 & 0.99 & Medium \\
\hline 3 & 24 & I suffer from unethical groups among the teachers in the school & 3.21 & 1.07 & Medium \\
\hline 4 & 23 & $\begin{array}{l}\text { I feel some teachers 'view is unfair to the physical education } \\
\text { teacher }\end{array}$ & 3.13 & 1.06 & Medium \\
\hline 5 & 20 & I suffer from poor social relationships with teachers at school & 3.04 & 1.01 & Medium \\
\hline 6 & 22 & I suffer from teacher interference in my work affairs & 2.95 & 1.01 & Medium \\
\hline \multicolumn{2}{|l|}{ General arithmetic mean of the dimension } & 3.24 & 0.75 & Medium \\
\hline
\end{tabular}

The results in Table (7) show that the arithmetic means ranged between (3.61-2.95), and the standard deviations for the items ranged between (0.97) and (1.07). Item (21) of "My colleagues' criticism of the physical education lessons disturbs me " ranked first with an arithmetic mean of (3.61) and a standard deviation of (0.97) with a medium degree of appreciation. Whereas item (22) of "I suffer from teacher interference in my work affairs" ranked last with arithmetic mean of (2.95) and a standard deviation of (1.01) with a medium degree of appreciation.

This may be attributed to the fact that constant criticism by teachers reduces the physical education teacher's sense of comfort at work, and weakens his confidence and ability, which increases his work pressure. It is also due to the physical education teacher's keenness to form good relations with his colleagues at work, and the knowledge of each teacher in the school about the job description of the profession, especially that any notes on the work of the physical education teacher in the school are transferred to the school's administration, is responsible for the performance of school workers, which led this item to come in the last order

Results related to answering the second question: What is the degree of practicing teaching competencies from physical education teachers' standpoint in the State of Kuwait?

To answer this question, the arithmetic means, and the standard deviation of physical education teachers' estimations in the State of Kuwait was calculated to the extent that they practiced teaching competencies in general.

Table 8: Arithmetic Means and Standard Deviations for the Estimations of Physical Education Teachers in the State of Kuwait to their Extent of Practice of the Teaching Competencies in General in Descending Order.

\begin{tabular}{|l|l|l|l|l|l|}
\hline Rank & $\begin{array}{l}\text { No } \\
\text { Dimension }\end{array}$ & Dimension Text & AM & SD & $\begin{array}{l}\text { Practice } \\
\text { Degree }\end{array}$ \\
\hline 1 & 2 & $\begin{array}{l}\text { Competencies for implementing the lesson "Employing } \\
\text { educational methods and aids" }\end{array}$ & 3.89 & 0.48 & High \\
\hline 2 & 1 & Lesson planning competencies & 3.85 & 0.47 & High \\
\hline 3 & 4 & Class management competencies & 3.70 & 0.57 & High \\
\hline \multicolumn{2}{|l|}{ Total teaching competencies } & 3.81 & 0.44 & High \\
\hline
\end{tabular}

Table (8) indicates that the degree of the practicing teaching competencies by the physical education teachers in the State of Kuwait, in general, came within the high degree of practice with an arithmetic mean of (3.81) and a standard deviation of (0.44). As for the dimensions, the dimension of " Competencies for implementing the lesson "Employing educational methods and aids" ranked first with an arithmetic mean of (3.89) and a standard deviation of (0.48) and with a high degree of practice, followed as a second rank by the dimension of" lesson planning competencies "with an arithmetic mean of (3.85) and a standard deviation of (0.47) with a high degree of practice. The dimension of " Class management competencies" ranked third and last with an arithmetic mean of (3.70) and a standard deviation of (0.57) and with a high degree of practice. 
As for the results of the items for each dimension of the practice of teaching competencies among physical education teachers, the results were as follows:

Results of the items related to the first dimension: Lesson planning competencies

Table (15) shows the arithmetic means and the standard deviations of the estimations of physical education teachers in the State of Kuwait to the extent of their exercise of the lesson planning competencies in descending order.

Table 9: Arithmetic Means and Standard Deviations for Physical Education Teachers' Estimations of the Degree of their Practice the Lesson Planning Competencies in descending order

\begin{tabular}{|l|l|l|l|l|l|}
\hline Rank & $\begin{array}{l}\text { No of } \\
\text { Item }\end{array}$ & Dimension of Stresses Related to Fellow Teachers & AM & SD & $\begin{array}{l}\text { Practice } \\
\text { Degree }\end{array}$ \\
\hline 1 & 2 & $\begin{array}{l}\text { I incorporate the teaching plan with arithmetic tools and devices and } \\
\text { educational techniques appropriate to achieve the objectives of the } \\
\text { lesson }\end{array}$ & 4.17 & 0.75 & High \\
\hline 2 & 7 & $\begin{array}{l}\text { I specify the skills and events that will be implemented during the } \\
\text { lesson in the plan }\end{array}$ & 4.11 & 0.74 & High \\
\hline 3 & 4 & $\begin{array}{l}\text { I take into account the financial and technical capabilities available at } \\
\text { school when preparing the plan }\end{array}$ & 3.93 & 0.87 & High \\
\hline 4 & 5 & $\begin{array}{l}\text { I take into account the time distribution of plans: annual, quarterly, } \\
\text { daily }\end{array}$ & 3.88 & 0.93 & High \\
\hline 5 & 1 & $\begin{array}{l}\text { I formulate educational goals in a measurable manner: cognitive, } \\
\text { performance and emotional }\end{array}$ & 3.82 & 0.86 & High \\
\hline 6 & 3 & $\begin{array}{l}\text { I take into account students needs and their developmental } \\
\text { characteristics when planning teaching }\end{array}$ & 3.70 & 0.87 & Medium \\
\hline 7 & 6 & $\begin{array}{l}\text { I plan to use physical local environment resources, such as stadiums } \\
\text { and gyms }\end{array}$ & 3.34 & 1.08 & \\
\hline \multicolumn{2}{|l|}{ General arithmetic mean of the dimension } & 3.85 & 0.47 & High \\
\hline
\end{tabular}

The results in Table (9) indicate that the arithmetic means ranged between (4.17-3.34) and the standard deviations for the items ranged between (0.74) and (1.08). Item (2) of "I incorporate the teaching plan with arithmetic tools and devices and educational techniques appropriate to achieve the objectives of the lesson" ranked first with an arithmetic mean of (4.17) and a standard deviation of (0.75) with a high degree of practice. Whereas Item (6) of "I plan to use physical local environmental resources, such as stadiums and gyms " ranked last with an arithmetic mean of (3.34) and a standard deviation of (1.08), with a medium degree of practice.

This is because sports tools, devices, and educational techniques are among the most important pillars of the physical education lesson, and without them, students are not given pre-defined physical skills, which makes the teacher focus on them when doing lesson planning. It is also because most Kuwaiti schools have the appropriate school environment for lessons of physical education, and the reason may also be due to the lack of coordination between the school administration and the authorities concerned with stadiums and gymnasiums, which leads a group of teachers to refrain from including their school plans to use stadiums and gyms outside the walls of the school

Results of the items related to the second dimension: competencies for implementing the lesson "Employing educational methods and aids"

Table (10) shows the arithmetic means and the standard deviations of the estimations of physical education teachers in the State of Kuwait to their extent of the practice of the competencies of implementing the lesson "employing educational methods and aids" in descending order. 
Table 10: Arithmetic Means and Standard Deviations for Physical Education Teachers' Estimations of the Degree of their Practice of Competences of Implementing the Lesson "Employing Educational Methods and Aids" in Descending Order

\begin{tabular}{|l|l|l|l|l|l|}
\hline Rank & $\begin{array}{l}\text { No of } \\
\text { Item }\end{array}$ & $\begin{array}{l}\text { Dimension of the Competencies of Implementing the Lesson } \\
\text { "Employing Educational Methods and Aids" }\end{array}$ & $\begin{array}{l}\text { AM } \\
\text { lesson }\end{array}$ & $\begin{array}{l}\text { Practice } \\
\text { Degree }\end{array}$ \\
\hline 1 & 9 & I do physical skills clearly and logically during the lesson & 4.25 & 0.77 & High \\
\hline 2 & 8 & $\begin{array}{l}\text { I use appropriate tools, physical equipment and educational } \\
\text { techniques for the lesson }\end{array}$ & 4.18 & 0.76 & High \\
\hline 3 & 10 & $\begin{array}{l}\text { I connect previous physical skills to new physical skills during the } \\
\text { lesson }\end{array}$ & 3.80 & 0.91 & High \\
\hline 4 & 11 & $\begin{array}{l}\text { I balance the theoretical and practical aspects of physical skills } \\
\text { during the lesson }\end{array}$ & 3.76 & 0.88 & High \\
\hline 5 & 15 & $\begin{array}{l}\text { I consider individual differences among students when learning } \\
\text { physical skills }\end{array}$ & 3.69 & 0.98 & Medium \\
\hline 6 & 13 & I use modern methods to teach physical skills & 3.61 & 0.97 & Medium \\
\hline 7 & 12 & $\begin{array}{l}\text { I use the teaching methods that adopt the principle of gradation in } \\
\text { learning physical skills from easy to difficult }\end{array}$ & 3.54 & 0.93 & \\
\hline 8 & 14 & & 3.89 & 0.48 & High \\
\hline
\end{tabular}

The results in Table (10) show that the arithmetic means ranged between $(4.32-3.54)$, and the standard deviations for the items ranged between (0.72) and (0.98). Item (9) of "I offer a practical model of physical skills in front of students during the lesson" ranked first with an arithmetic mean of (4.32) and a standard deviation of (0.72) and with a high degree of practice. Whereas, item (14) of " I use the teaching methods that adopt the principle of gradation in learning physical skills from easy to difficult " ranked last with an arithmetic mean of (3.54) and a standard deviation of (0.93), and with a medium degree of practice.

This is because new physical skills for students need to be demonstrated by the teacher in practice in front of students to be able to perform them properly and that some teachers believe that physical skills for students in the second stage are not complicated. It is also because they do not need to use educational methods and aids characterized by the transfer of those skills for students to graduate from easy to difficult, and perhaps these methods being specialized aids are not available in Kuwaiti schools as required.

Results of the items related to the third dimension: competencies for assessing educational outcomes

Table (11) shows the arithmetic averages and the standard deviations of physical education teachers' estimates in the State of Kuwait to the extent of their exercise of the competencies of assessment educational outcomes, in descending order.

Table 11: Arithmetic Means and Standard Deviations for Physical Education Teachers' Estimations of the Degree of their Practice of Competences of Assessment Educational Outcomes in Descending Order

\begin{tabular}{|l|l|l|l|l|l|}
\hline Rank & $\begin{array}{l}\text { No of } \\
\text { Item }\end{array}$ & $\begin{array}{l}\text { Dimension of the Competencies of Assessment of Educational } \\
\text { Outcomes" }\end{array}$ & AM & $\begin{array}{l}\text { SD } \\
\text { Degree }\end{array}$ \\
\hline 1 & 18 & $\begin{array}{l}\text { I treat physical skills assessment as being different from other } \\
\text { subjects' skills }\end{array}$ & 4.13 & 0.76 & High \\
\hline 2 & 16 & $\begin{array}{l}\text { I diversify the assessment techniques according to the diversity of } \\
\text { goals and levels }\end{array}$ & 3.65 & 0.99 & Medium \\
\hline 3 & 20 & $\begin{array}{l}\text { I use the different types of assessment: introductory, structural, and } \\
\text { cumulative }\end{array}$ & 3.58 & 0.97 & Medium \\
\hline 4 & 17 & I use specific, measured tests for skills and fitness & 3.49 & 0.93 & Medium \\
\hline 5 & 19 & I use the final assessment that takes place at the end of each lesson & 3.47 & 0.96 & Medium \\
\hline 6 & 22 & $\begin{array}{l}\text { I use monitoring, delisting lists and records to document the } \\
\text { assessment results }\end{array}$ & 3.33 & 1.08 & Medium \\
\hline 7 & 21 & $\begin{array}{l}\text { I use the assessment results to design remedial and enrichment } \\
\text { activities }\end{array}$ & 3.24 & 1.06 & Medium \\
\hline
\end{tabular}

The results in Table (11) indicate that the arithmetic means ranged between $(4.13-3.24)$, and the standard deviations for the items ranged between (0.76) and (1.08). Item (18) of "I treat physical skills assessment as being different from other subjects' skills" ranked first in terms of practice, with an arithmetic mean of (4.13) and a standard deviation of (0.76) with a high degree of practice. Whereas item (21) of "I use the assessment results to design remedial and enrichment activities" ranked last with an arithmetic mean of (3.24) and a standard 
deviation of (1.06), and with a medium degree of practice.

This result is due to the logical fact that physical skills need muscular, mental and visual synergy in which most of the body's organs are employed, and therefore the evaluation of these skills requires an assessment of the student's various mental and physical abilities. It is also some teachers who do not have sufficient ability to design remedial and enrichment activities for physical skills because the supervisor of physical education did not focus on curative and enrichment activities.

\section{Recommendations}

In light of the results of the current study, the following has been recommended:

1. Holding training courses for physical education teachers with short experience continuously to familiarize them with how to face and overcome work stresses, so that these stresses do not negatively affect their practice of teaching competencies.

2. Paying attention to building bridges of communication between the physical education supervisors and teachers through individual and group meetings to exchange views and points of view to discuss educational problems faced by teachers, and in this way, which contributes to alleviating the work stress of physical education teachers, especially those related to educational guidance.

3. Instructing physical education supervisors to work to raise the practice of physical education teachers to the competencies of evaluating educational outcomes, through holding training courses for the competencies of evaluating educational outcomes in physical education lessons.

4. Designing counseling programs to help physical education teachers adapt to their sources of work stress, especially teachers with short experience.

\section{References}

Bhargava, A., \& Pathy, M. (2011). Perception of student teachers about teaching competencies. American International Journal of Contemporary Research, 1(1), 77- 81.

Hamaideh, Ola. (2011). The level of work pressure among secondary school teachers in public schools in Jordan and the problems caused by it. Journal of Studies, Educational Sciences, 38, 298-316.

Hamad, Mashael. (2015). Work stress and its relationship to job performance for male and female independent school teachers in Qatar. Unpublished Master Thesis, University of Jordan, Amman, Jordan.

Ismail, Riyadh and Aziz, Muhammad. (2010). Occupational stress and its relationship to organizational deviations of teachers and teachers of physical education in the Nineveh Governorate Center, research presented at the eighteenth periodic conference of colleges of physical education in Iraq.

Khleifat, Abdel-Fattah and Al-Matarna, Sherine. (2010). The impact of work stress on the job performance of principals of government basic schools in the south of Jordan. Damascus University Journal, 26, 599-642.

Kuchinsky, C. (2009). The most stressful jobs in America. Retrieved from: www.Associatedcontent.com/article/92667/the_most_stress ful_jobs_in_america.html. 15- February, 2016

Malika, Scharf. (2011). Sources of occupational stress among Algerian teachers: a comparative study in the three educational levels (primary, intermediate, and secondary). Unpublished Master Thesis, University of Mouloud Mammari, Tizi-Ouzou - Kabylia, Algeria.

Masdar, Abdul Azim and Abu Kweik, Bassem. (2007). The pressures of the teaching profession and its relationship to the dimensions of mental health among teachers and teachers of the lower basic stage in the Gaza Strip - Palestine -. Research presented to the third educational conference "Quality in Palestinian Education - An Introduction to Excellence", held at the Islamic University from October 30-31.

Matrafi, Sulaiman. (2001). Administrative communication obstacles and their impact on the level of work pressure. Unpublished Master Thesis, Naif Arab University for Security Sciences, Riyadh, Saudi Arabia.

Muslim, Muhammad. (2007). An Introduction to Work Psychology. Algeria: Cordoba Publishing and Distribution House

Pines, A. (2004). The emotions of teacher stress. Teaching and teacher Education, 20, 537-541.

Saleh, Nassima. (2015). Occupational pressures for teachers of physical education at the intermediate and preparatory levels. Journal of Physical Education Sciences, Iraq, 1, 90-102

Sharif, E. (2010). Evaluation of student, teacher teaching competencies in the curricula and teaching methods of motor expression in the light of quality academic standards. World Journal of Sport Sciences, 5, 331-358. 